\title{
TAKE IT YA 3AZIZI: CODE-SWITCHING ON FACEBOOK BY JORDANIAN BILINGUALS
}

Mutasim Al-Deaibes, Khalifa University, Abu Dhabi, UAE, mutasim.aldeaibes@ku.ac.ae

\begin{abstract}
This study scrutinizes the structural aspects of Jordanian Romanized Arabic-English code-switching (CS) on Facebook. All posts examined are written in Romanized Arabic, a new trend of writing on computer-mediated communication (CMC). Three types of CS are examined, i.e., inter-sentential, intra-sentential, and tags, though the greatest focus is on the intra-sentential instances because of their syntactic complexity. Different syntactic categories are examined and critically scrutinized. Finally, the validity of two controversial syntactic constraints, i.e., the Equivalence Constraint (EC) and the Free Morpheme Constraint (FMC) by Poplack (1980) are tested. The findings show that nouns and noun phrases are the most frequently used type of switches among the other syntactic categories, i.e., verbs and verb phrases, adjectives, adverbs, prepositions and prepositional phrases, and pronouns. The results also obviously reveal that there is a violation to the two constraints, namely The Free Morpheme Constraint and The Equivalence Constraint.
\end{abstract}

Keywords: Code-switching, bilingualism, Romanized Arabic, CMC, Jordanian Arabic

\section{INTRODUCTION}

This study examines the syntactic constraints on Jordanian Arabic ${ }^{1}-$ English code-switched Facebook posts. Code-switching (CS), the rapid succession of several languages in a single speech event (Muysken, 2000), is considered by many sociolinguists as one of the most obvious, common and natural consequences of active bilingualism (Bader and Minnis, 2000). It is a sociolinguistic phenomenon that is often found when more than one language is in contact within the same community.

\footnotetext{
${ }^{1}$ For more information about the dialect, see Al-Deaibes, 2016b, 2021; AlDeaibes and Rosen, 2019.
} 
Thus, to be able to code-switch, you need to be at least ${ }^{2}$ bilingual or bidialectal.

CS is not confined to oral conversations; it may also take the form of written discourse. However, unlike oral interaction, written communication allows users to modify or edit their messages before sending them to the other party. Recently, a growing number of studies have looked at the phenomenon of CS in computer-mediated communication (CMC), such as e-mails (Durham, 2003), instant messaging (Ho, 2006; Palfreyman et al, 2003), mobile phones (Al-Khatib and Sabbah, 2008). These studies conclude that bilinguals use English besides their native languages when they enrol in any communication that discusses educational and technological matters. In this study, I aim to re-examine the hypothesized universal validity of the two syntactic constraints, i.e., Poplack's (1980) Free Morpheme and Equivalence constraints in the light of the Arabic/English CS on the social network of Facebook. Also, since Facebook posts are asynchronous, I hypothesize that Jordanian bilinguals do not violate the above-mentioned constraints when they code-switch because asynchronous communication enables them to reread their posts and edit them before sending them to the other party. I also hypothesize that Jordanian bilinguals are able to produce different types of CS.

\section{WRITING SYSTEMS AND CMC IN JORDAN}

\subsection{Writing Systems on CMC}

With the rise in popularity of the Internet and the diverse types of CMC, Arabic-speaking youth in the Middle East and North Africa and Arab expats have developed a special form of writing that allows them to informally communicate with each other and use a new system of writing that is understandable only among themselves via e-mails, textmessaging, chats, etc.

The Romanized writing system of Arabic is simply a combination of English alphabets and numbers. It emerged with the invention of mobile phones in the 1990s, when users had to use the English keypads to send text messages because at that time the keypads did not support the Arabic alphabet. Accordingly, it became habitual that people use this form of writing even after the emergence of the Arabic keypads. The Romanized writing system of Arabic uses English letters to represent the equivalent Arabic phonemes that sound the same in both English and Arabic, whereas it uses numbers to represent Arabic phonemes that do

\footnotetext{
${ }^{2}$ The word Bilingual is used to refer to those whose Arabic is their mother tongue and English is their second language.
} 
not exist in English. These numbers are used as a phonetic transcription for the Arabic phonemes (see Table 1). Many studies report that people use Romanized Arabic because they are more experienced and faster in typing in English than in Arabic (see Al-Khatib and Sabbah 2008; Palfreyman and Al Khalil 2003; Ghanem 2011, Al-Deaibes 2016a). Consequently, most commercials, advertisements, movie titles and flyers targeting teenagers and young adults have started using this new system of writing. For example, some Arabic music websites have recently started to use the Domain Name Systems (DMS) in Romanized Arabic like 6arab.com and fann3arabi.com, among others, to catch the youths' attention (Aboelezz, 2009).

Table 1: English Numbers and their Phonetic Equivalences in Arabic

\begin{tabular}{|c|c|c|}
\hline $\begin{array}{l}\text { English } \\
\text { Numerals as } \\
\text { Used in } \\
\text { Romanized } \\
\text { Arabic }\end{array}$ & Equivalent Sound in Arabic & $\begin{array}{l}\text { Arabic } \\
\text { Character }\end{array}$ \\
\hline 2 & Voiceless Glottal Plosive & $\varsigma$ \\
\hline 3 & Voiced Pharyngeal Fricative & $\varepsilon$ \\
\hline $3^{\prime}$ & Voiced Velar Fricative & $\dot{\varepsilon}$ \\
\hline 6 & Voiceless Emphatic Alveolar Plosive & b \\
\hline $6^{\prime}$ & Voiced Emphatic Interdental Fricative & ظ \\
\hline 7 & Voiceless Pharyngeal Fricative & $\tau$ \\
\hline 7'or 5 & Voiceless Velar Fricative & $\dot{\tau}$ \\
\hline 8 & Voiceless Uvular Plosive & ق \\
\hline 9 & Voiceless Emphatic Alveolar Fricative & ص \\
\hline 9 ' & Voiced Emphatic Alveolar Plosive & ض \\
\hline
\end{tabular}

The use of this new trend of writing is considered a new type of CS since it alternates between two languages, i.e., Arabic and English. In this study, I refer to this form of writing as Romanized Arabic because Facebook users use English alphabets and numbers whether they want to communicate in Arabic or to switch between Arabic and English. Therefore, this type of writing is a hybrid method of written communication in the Arab World.

\subsection{Linguistic study of CMC}

$\mathrm{CMC}$ refers to the communication that is carried out between computer users. This communication can be synchronous or asynchronous. While the former refers to real time communication like chat rooms or instant 
messenger, the latter refers to delayed response communication like emails text messaging, Facebook comments, etc. Crystal (2006) views $\mathrm{CMC}$ as an emerging third medium of communication, a hybrid form that combines oral and written language features. CS on CMC has received little attention in the literature in general as opposed to CS in face-toface communication. What gives this study its importance is the fact that, when it comes to studying the linguistic constraints on asynchronous CMC generally or Facebook particularly, it is the second to none, to the best of my knowledge.

\section{Syntactic Constraints on CS}

From a syntactic viewpoint, CS involves utterances from one language that are syntactically integrated into another language (Poplack, 1980). Such integration may occur at a clause or sentence boundary (intersentential CS), within a phrasal boundary (intra-sentential CS) or an insertion of a tag or short phrase like I mean, you know, OK, alright, Oh, my god) (tag-switching) (Myers-Scotton, 1993; Kanakri and lonescu, 2010). In her seminal study of Spanish/English CS among Puerto Ricans in New York, Poplack (1980) distinguishes between tag-switching or emblematic CS, inter-sentential CS, and intra-sentential CS. Tagswitching involves inserting a tag or short phrase (e.g., I mean, you know, OK, alright, Oh, my god) in one language into an utterance that is otherwise entirely in another language. Tags can be placed anywhere in the utterance without violating any grammatical rule. These examples occur frequently because they contain minimal syntactic restrictions, and thus their insertion does not usually violate any syntactic rule. Intersentential CS occurs outside the sentential or clausal level, that is, each sentence or clause is in a different language. Lastly, intra-sentential CS takes place at the phrasal level.

The constraints that I will test in this study are Poplack's (1980) Free Morpheme Constraint and Equivalence Constraint. The Free Morpheme Constraint forbids a code-switch between a bound morpheme and a lexical form unless the lexical form is phonologically integrated into the language of the bound morpheme. Poplack provides an example of an unacceptable code-switch that violates the Free Morpheme Constraints:

\section{1. *Estoy eat-iendo}

Am eat-ing

'I am eating.'

According to Example (1) above and based on the Free Morpheme Constraints, the violation occurs because the Spanish bound morpheme -iendo is used with the English verb eat. Accordingly, in order for the 
utterance in Example 10 to be acceptable and permissible, the verb eat should be used with the English progressive suffix -ing instead of using the Spanish suffix.

The Equivalence Constraint states that CS occurs at points where the juxtaposition of elements from the two languages does not violate a syntactic rule of either language, that is, where the surface structure of two languages coincides. The Equivalence Constraint states that CS occurs at points where the surface structures of the two languages are similar. This has to do with the word order of the two languages where the CS utterances must be grammatically possible in the two languages.

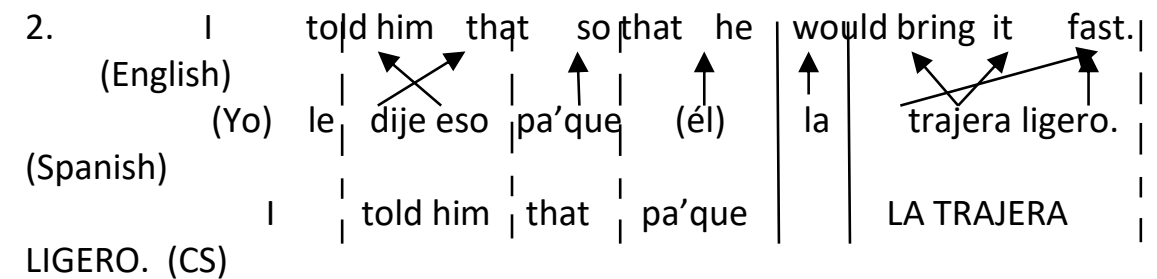

\section{METHODOLOGY}

\subsection{Research Questions}

In this study, I aim to investigate the hypothesized universal validity of the two syntactic constraints, i.e., the Free Morpheme and Equivalence Constraints in the light of the Arabic/English CS on Facebook. My hypothesis in this study is that Jordanian bilinguals do not violate the above-mentioned constraints when they code-switch because asynchronous communication enables them to read their posts and edit them before sending them to the other party as opposed to oral CS where the speech is more natural and spontaneous.

\subsection{Participants}

Participants are 30 (16 males and 14 females) Arabic/English Jordanian bilinguals whose L1 is Arabic and L2 is English. Their proficiency in L2 does not vary significantly. They are all university graduates with ages ranging between 27 and 39 years old (age mean=31.4). They all studied English in schools from grade five to grade twelve and took some courses in English at the university level. At the time of collecting data, they were all living in Irbid, a city in the north of Jordan.

\subsection{Data Collection and Coding}

A total of 1650 posts, with a total of 2000 instances of CS, were collected from the ten bilinguals' profiles on Facebook. Types of postings that are scrutinized take the form of status updates, wall-to-wall comments, 
photo and video posts comments, etc. All these postings are characterized as asynchronous, i.e., they are not real-time conversations where the author and the participants are communicating at the same time. Some of these posts contained more than one example of CS (e.g., intra-sentential and tag). The CS instances collected are written in Romanized Arabic and English. The data collected are divided into three categories: inter-sentential, intra-sentential, and tag CS as proposed by Poplack (1980). Further, all intra-sentential occurrences of CS are tallied and classified according to their syntactic category, i.e., nouns, noun phrases, prepositions, preposition phrases, pronouns, etc.

\section{RESULTS}

\subsection{Types of CS As Produced by Facebook Users}

Out of the 2000 occurrences, $31 \%(n=620)$ occurrences involved intersentential, $60 \%(n=1200)$ switches involved intra-sentential CS, and $9 \%$ $(n=180)$ involved tag-switches as shown in Figure (1) below.

Figure (1): Types of CS

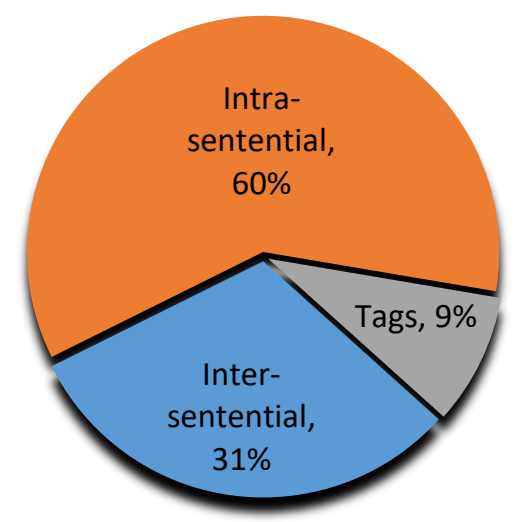

\subsection{The Most Commonly Switched Syntactic Categories}

Figure (2) below shows how these intra-sentential switches are distributed according to the major syntactic categories. The total number of inter-sentential switches as classified according to the major English parts of speech is 1900 . Nouns and noun phrases are $61 \%$ $(n=1150)$ switches, as one syntactic category, whereas verbs and verb phrases comprised $7 \%(n=140)$ examples as one category. While adjectives are $17 \%(n=330)$, adverbs are only $6 \%(n=120)$ switches and no examples of adjective phrases or adverb phrases were found in the 
data. There are $5 \%(n=90)$ prepositions and prepositional phrases as one category. Finally, there are $5 \%(n=70)$ pronouns.

Figure (2): Distribution of Intra-Sentential Switches onto the Syntactic Categories



\section{DISCUSSION}

\subsection{Types of CS as Produced by Facebook Users}

\subsubsection{Inter-Sentential CS}

Although inter-sentential CS is the easiest type to produce because it occurs outside the clause or sentence boundary (Poplack 1980), it is not the most frequent type of CS in my corpus. Out of the 620 occurrences of inter-sentential CS, bilinguals used $67 \%(n=420)$ examples where English is the matrix language, while $33 \%(n=200)$ examples were used where Arabic is the embedded language. This also shows that Jordanian bilinguals prefer to start with English rather than Arabic when it comes to alternating between the two languages at the clause level (intersentential), and also English appears to be the dominant language in their online written communication. It further indicates that Jordanian bilinguals' proficiency and fluency in English enables them to go beyond switching at the word level to a level that involves more syntactic complexity or difficulty. The following are some examples on this type of CS: 
3. I will try my best [la tehkal ham wakelha la Allah]

no bear worry trust in God

'I will try my best [don't worry, trust in God]'

4. That's life... [garaf w ta3ab 3al fa9'i]

Disgust and tire on empty

'That's life...[disgusting and tiresome for nothing]'

5. Get ready man. [ana 6ale3]

going

'Get ready, man. [I am leaving]'

This finding corroborates Abalhassan and Alshalawi (2000) who found a correlation between the level of complexity of bilingual code-switches and the participants' level of proficiency in English. The higher the level of proficiency, the more complex the switching is. Less complex switches involve switching at the word level, whereas more complex switching involves switching larger constituents, i.e., clauses and sentences.

\subsubsection{Intra-Sentential CS}

The intra-sentential occurrences comprised $60 \%(n=1200)$ of the total number of examples, making it the most commonly used type of CS in my corpus. It is the most commonly used type of switches in the Facebook users' written communication. Although this type, according to Poplack (ibid), is syntactically complex, it is still the most frequent among all types. This can be attributed to the correlation between the level of proficiency of each speaker and the level of complexity of CS. The higher the level of proficiency, the more complex the switching was. This also leads to the conclusion that the participants have a good command of English that enables them to make some English words fit in the Arabic sentences. As clearly shown in Examples (6-9) below, Facebook users shifted from one language to another at major constituent boundaries despite the risk of violating the syntactic rules in either language.

6. el [business] slow bi [decemeber] elnas betkoon 6afraneh looool The in people be broke laugh out loud

'The business is slow in December. People will be broke.'

7. masmoo7lak bas [two pieces] w [carry on] heik metzakir You're allowed only and like this I remember 'You are allowed only two pieces and a carryon as I remember.' 
8. aham

$$
\text { eshi bel }
$$

insurance]

Most important thing in the

[contract] eno ykon fi [health

'It is important that the contract include health insurance.'

9. Ro7t w 7akali ha9' [viral infection] $: * \theta$

I went and told-me this

'I went and he told me it is viral infection.'

This shift from one language to another at major constituent boundaries is ascribed to the fact that the two languages have different word orders. While JA is an SVO and VSO, English in only an SVO language.

\subsubsection{Tag-Switching}

The third type of switches consisted of $9 \%(n=180)$ occurrences. As shown in the examples below, tag-switching take the form of either a single word insertion or using culture-specific expressions such as oh, wow, my god, crap! Damn it! and so forth. Young bilinguals almost always use English tags because they listen to them when they watch foreign movies and sometimes, they use them as a way of showing off that they know some English words (see San, 2009). This type of switching does not interfere with the use of the Matrix language, i.e., Arabic, because they do not trigger any syntactic violation.

10. Okie-dokie bkamelha w bab3athlak message complete-it and send-you message

'[Okie-dokie] I will finish it and send you a message.'

11. Ok... ra7 a6la3 kman sa3a...

will go after hour

'[OK] I will leave in an hour.'

12. Oh my lord!!! Rasi bedo yetfajar min eltafkeer. my head want blast from the thinking

'[Oh my lord!] My head is about to explode because of thinking.'

Finally, the above-mentioned results are in agreement with my hypothesis that Jordanian bilinguals are able to produce different types of CS. The results also concur with those of Poplack (1980) that there is a correlation between high competence of $L 2$ and high frequency in all 
types of CS. Facebook users were successful in using the three different types of CS though tag-switching was not very common as the other two types of CS.

\subsection{The Most Commonly Switched Syntactic Categories}

\subsubsection{Nouns and Noun Phrases}

The number of examples of single nouns and noun phrases combined is the largest in the data, comprising 1150 instances (61\%) of the total switches. Out of theses switches, English nouns are used 850 times (45\%), and noun phrases are used 300 times (16\%). As for the English switched nouns, $78 \%(n=670)$ are technical or professional terms that people use in everyday life or that have no equivalence in Arabic like mall, wall, visa, sale, message etc. Such nouns include, but are not limited to, computer-related terms such as messages, connection, technology, motherboard, inbox, comment, mobile, etc.; academicrelated topics such as chapter, course, doctor, class, article, library, paper, meeting, etc.; leisure-time-related terms such as vacation, mall, weather, picture, weekend, airport, visa, sale, etc. However, it is hard to decide whether these single (lone) nouns are examples of CS or borrowing since they are used in $\mathrm{CMC}$, which makes it hard to decide whether they are phonologically or morphophonemically (according to Poplack, 1988) integrated to the guest language, that is, Arabic. According to Mustafawi (2002), lone words that follow the structure of the matrix language are considered code-switches while lone words that follow the structure of the embedded language are considered borrowings. Out of the 850 single nouns, there are $14 \%(n=170)$ English nouns that are connected to the Arabic definite article (prefix) 'el' such as 'el-weekend, el-chapter, el-leader, el-coffee,' and 50 nouns that are connected to the Arabic plural marker (suffix) ' $a t$ ' and the possessive marker '-ak' such as 'e-mail-ak, mobil-ak, messag-at, offer-at.' Although these English nouns are connected to Arabic bound morphemes and behave like the Arabic-origin nouns, we still cannot decide if they are phonologically integrated in Arabic on $\mathrm{CMC}$, and thus will be treated as CS examples due to lack of information on written communication CS.

As for the English switched noun phrases, most of them are used as collocations (a combination of words that are commonly used together) such as down payment, viral infection, bacterial infection, job offer, rush hour, public sector, etc. Syntactically, the English nouns and noun phrases used where Arabic is the Matrix language can be assigned different theta roles as shown in the Examples below (13-15). They take the position of subjects as in Example (13) where the Arabic definite article $e l$ is used with the noun to indicate that it is a definite noun that 
is preceded by a determiner. The noun phrase job offer in Example (14) is used as a direct object, while accident in (15) is an object of a transitive verb. It is worth mentioning that throughout the data, there was no single example of an indirect object because indirect objects in Arabic are bound morphemes which are always attached to the verbs when they are used as pronouns. Thus, an insertion of an English indirect object is not permissible because it cannot be attached to the Arabic verb.

13. El mall eljedeed be5zi ktheeer kal 3adeh

The the-new ugly much like habit

'The new mall is very shameful as usual.'

14. 7awil tlagele job offer honak plz plz plz

Try find-me there, please

'Try to find me a job offer there please!'

15. Sme3it 3amil accident.. sa7ee7?

I-heard made correct

'I heard you had an accident, is that true?'

Also, nouns were found in the position of objects of prepositions as in Example (16) where the noun price is preceded by the Arabic preposition bel, meaning in. In short, nouns and noun phrases are the majority among the other syntactic categories and have been found in different grammatical positions: subjects, objects, direct objects, and objects of prepositions.

16. Kolo included bel price (-) egraha mara thanye All in-the read-it once two

'All is included in the price. Read it again.'

\subsubsection{Verbs and Verb Phrases}

English verbs and verb phrases only appear 140 times (7\%), which is far fewer times than the nouns, noun phrases, and adjectives as shown in the previous sections. Single verbs are used 80 times (4\%), while verb phrases are used 60 times (3\%) of the total number of switches. Thirty verbs out of the 80 were used in an interesting yet thorny way. As shown in Examples (17-19) below, these verbs are connected to the Arabic accusative second person pronoun - $a k$ and/or using the future marker $b a$ - as if the verb were an Arabic verb not English.

17. Missak ktheer!

Miss-2SM-ACC a lot

'Miss you a lot!' 
18. Ok.. ra7callak basawsal el bait.

Will call-2SM-ACC when arrive the home

'Ok..I will call you as soon as I get home.'

19. kman sa3aw bacallak awal ma awsal:P

after hour and FUT-call-2SM-ACC first when arrive

'I will call in one hour when I arrive.'

In Example (20) below, the verb kill is used in a quotation. The participant in this example tried to quote a warning that is written on a packet of cigarettes to show his resistance to this warning and also by using the English verb gives in the same quotation again to reinforce the resistance in the same language: English. Thus, the use of the verb phrase gives $u$ a life in the same sentence is triggered by the use of the verb kills which is like the participant's intension to make a kind of parallelism by using the two verbs from the same language to show his resistance.

20. Katbeen 'smoking kills' wallah eno gives $u$ a life min ele benshofo !!

They-wrote by god that from that we-

see

'They wrote, 'smoking kills' By God it gives you life based on what we see.'

A more complicated example that appeared in a verb phrase is given in Example (21), where the verb is originally English (hack); however, the participant conjugated the verb using the Arabic inflections $a$ and er which are used to make the verb in the infinitive form, namely, to hack. This verb 'ahacker' means 'to hack' in English, but the participant has chosen to make it sound like its equivalent verb in Arabic 'aqarsin'.

21. 7ada b3raf kef momkin ahacker antivirus.. ma bedi adfa3 120 dollar

One know how able hack antivirus. Not want pay 120 dollar

'Does anyone know how to hack an antivirus. I don't want to pay $\$ 120$.

\subsubsection{Adjectives}

English adjectives within the Arabic sentences are the second largest portion of switched syntactic categories after nouns and noun phrases. 
They constitute $17 \%(n=330)$ switches of the total number of intrasentential switches. The most frequent adjective that appeared in the posts of the participants is the word nice. It was used $24 \%(n=80)$ in the intra-sentential occurrences. English adjectives as used in the posts of the participants are mainly used to describe places $39 \% \quad(n=130)$ (Example 34), to use popular English expressions 3\% $(n=10)$ (Example $35)$, to express feelings (Example 36$) 21 \%(n=70)$ to talk about technical terms (Example 37) $21 \%(n=70)$, or describing objects $16 \% \quad(n=50)$ Moreover, it is worth noting that the attributive English adjectives are used within the framework of the Arabic sentences, i.e., Arabic is the Matrix language. This is because adjectives in English are prenominal whereas adjectives in Arabic are postnominal. Similarly, the predicative adjectives are used within the framework of the Arabic sentences where the sentence lacks a copular verb. English does not allow predicative adjectives to appear without a copula, as in (22). As Example (22) below shows, the adjective nice is not used prenominally as it should be. Rather, it is used postnominally as if it were an Arabic word to fit in the Arabic sentence. The grammaticality of this type of usage will be discussed in the next section. In Example (23), the participant used this familiar English expression 'slow but steady' to describe or justify his situation of being late on graduation. Thus, in this expression, two English adjectives are used, slow and steady.

22. Wein hay elpic metsawerha. wow wallah elmanthar nice. Er7amna!!!

Where this the-picture you-shoot-it I swear the scenery mercy on us

'Where is this picture taken? Wow. By God it is nice scenery. Have mercy on us!'

23. Saneh $w$ ba5la9 min hal shit... slow but steady $(-)$ A year and I-finish from this shit

'It is only one year and will get it over with... slow but steady.'

In Example (24) below, the participant used the compound adjective brokenhearted and the adjective lonely to express his sad feelings. Since these two adjectives are used predicatively not attributively, they do not violate the English prenominal adjective rule.

24. ana brokenhearted wlonely 2 3eeshe betgarfi wallah and life disgusting. I swear. 'I am broken-hearted and lonely. By God, life is disgusting.' 
In Example (25) below, the participant used the adjective confusing to describe the last page in the article. In other words, the adjective confusing is used to describe the English noun 'page' which triggers the use the English adjective. This adjective is used predicatively in the sentence, which is why it is not followed by a noun or a noun phrase.

\section{Greet kol el article bas el page el a5eereh confusing ktheer I-read all the but the the-final a lot I read the article, but the last page is confusing a lot.}

\subsubsection{Prepositions and Prepositional Phrases}

English prepositions and prepositional phrases constitute 90 switches of the total number of intra-sentential switches (5\%). Throughout the data, if a noun following the English preposition were an English noun, it would be considered as a prepositional phrase, not a preposition; and if the noun following the English preposition were an Arabic noun, then it would be considered a single preposition. Switches involving single prepositions occur only thirty times $(1.7 \%)$, whereas those involving prepositional phrases occur sixty times (3.3\%). This may be attributed to the fact that there are many fewer Arabic (Standard or Colloquial) prepositions than English ones (Al-Qudhai'een, 2003: 77). Example (26) below shows how the English preposition for is used and followed by the Arabic nouns phrase sheesha; thus, it is classified and labeled as a single preposition, not a prepositional phrase.

26. Ok... ra7 a6la3 kman sa3a 7ada interested yroo7for sheesha? will go after hourone go hookah

Ok! I am leaving in an hour. Anyone interested in going for Hookah?'

Examples (27 and 28) show how English prepositional phrases are used in the intra-sentential CS. In both examples the prepositions in and on are followed by English noun phrases and both are instances of temporal prepositions because both prepositions are followed by time expressions; in is followed by ' 15 minutes' and on is followed by 'time.'

27. Raye 7 3l meeting in 15 mins

I-going for-the

'I am going to the meeting in fifteen minutes.'

28. Ok.. ra7 akkon on time enchalla.

will be god willing

'Ok. I will be on time hopefully.' 
The prepositions for $^{3}$ and in in Example (29) are both followed by English nouns phrases. The preposition for is followed by the pronoun you ${ }^{4}$ whereas the preposition in is followed by the noun both. Example (30) shows how the English preposition in is used as locative preposition followed by the proper name (name of a place), making up a prepositional phrase.

29. Gayeb... waiting $4 u$ in both bel gym $w$ bel course Ok for you in-the and in-the Ok. I am waiting for you in both the gym and the course.'

30. Sme3it fi 3ndko storm in kansas, sa7ee7? Stay safe man.

I-heard there is on your side correct?

'I heard there is a storm in Kansas, right? Stay safe, man.'

In Example (31) below, the English preposition to is used three times in a single sentence. In the first position it is followed by the English pronoun you making up a noun phrase. In the second position it is preceded by the English conjunction and which triggers the use of the English words which are adjacent to them. However, in the third position it is used between the Arabic conjunction wa and the Arabic proper noun Ahmad. My speculation here is that since the preposition to is used twice in the same sentence, the speakers found it easier to use it as a third time to make the sentence sound more consistent.

31. Ah twins. Alf mabrook to $u$ and to Mervat wa to Ahmad basha of course

A thousand congrats and mister

'Oh twins! Congratulations to you, to Mervat, and to Mr. Ahmad, of course.'

\subsubsection{Adverbs}

English adverbs are not very common in the data, comprising only 120 switches (6\%) of the total number of the intra-sentential occurrences. This result is also reported by Alenezi (2001) and Al-Qudhai'een (2003). According to Al-Qudhai'een (2003), the low frequency of English adverbs

\footnotetext{
${ }^{3} \&^{5}$ This is a common practice in CMC communication, the numeral 4 is used as a symbol for the English preposition for, and the letter $u$ is for the second person pronoun you.
} 
when bilinguals code-switch between informal Arabic and English is ascribed to the fact that speakers do not usually use adverbs as frequently as they do when they speak Standard Arabic or when they use English (p. 74). My explanation why adverbs are not common in my data is attributed to my speculation that adverbs (excluding adverbs of frequency and time-related one in my database) always need a verb to modify. So, with the absence of many English verbs in the posts and the use of Arabic verbs instead, the participants preferred to use Arabic adverbs, resulting in a few English adverbs. The four Examples (32-34) (out of the total twelve occurrences) are all adverbs that are timerelated. The other adverbs are here, really, and much. The following examples illustrate how the English adverbs are used in the data.

32. a5eeran ra7 agdar agadim again 3la admission lal grad school

finally will be-able apply on-the. for

'Finally, I can apply to get admission in grad school.'

33. Gadamit 3ala funding min eljam3a bas still ma radoli $5 a b a r \ldots$

I-applied on-the from the-university but no replied news

'I applied for funding at the university but still didn't hear back from them.'

34. ana already registered lalcourse

bas elmoshkele min 8-9:15 $\odot$

1 for-the-course but the-problem from 'I am already registered in the course but the problem is that it is from 8-9:15.

\subsection{The Syntactic Constraints}

\subsubsection{The Free Morpheme Constraint}

One element of Poplack's (1980) Free Morpheme Constraint relies on phonological integration as a criterion. As the data under investigation is textual in nature, there is little phonological information available; therefore, I will present many counterexamples that invalidate Poplack's constraint in my study. It is worth mentioning here that the definite article in Standard Arabic is al whereas in JA as well as in other varieties of spoken Arabic the definite article is el or il. Also, some JA speakers (or Facebook users in this study) assimilate the Arabic definite article to the following English word as shown in Example (35) where the users 
dropped the $I$ and used $S$, which already exists in the word security, because the two sounds are adjacent. So, in the same example, the participant was trying to write the assimilated definite article the way it is pronounced in spoken utterances without adding another ' $s$ '. This phonological process was also reported by Al-Enazi (2002). In Example (35) below, the phonologically assimilated JA definite article el (which became $s$ after undergoing assimilation) is cliticized to the English noun security and none of the two words is phonologically integrated to the other language. However, since the corpus of this study is taken from written conversations not oral ones, it is hard to predict if the lexical item security is phonologically integrated in the language of the bound morpheme, which is Arabic.

35. Bastana esecurity check min el mo5abrat

I-waiting the from the-intelligence

'I am waiting for the security check from the intelligence.'

\subsubsection{The Equivalence Constraint}

The data of this study refutes the universality of this constraint by violating it in different ways. The following counterexample (36) shows how Jordanian bilinguals switched between English and Arabic in their posts and violated the Equivalence Constraint. The participant violated this constraint by using the English attributive adjective nice after the Arabic noun 3o6la (vacation). The participant here treated the Arabic noun 3o6la as if it were an English noun just to make it fit with the English adjective nice, which violates the structure of Arabic where the adjective comes after the noun. In this example, again, the subject treated English as the host languages, whereas Arabic is the embedded language.

36. ngarir sho ne3mal bel 3o6la el nice ;) decide what we-do in-the vacation the 'Decide what to do in the nice vacation.'

Similarly, in Example (37) where Arabic is the host language, as most of the data is for intra-sentential CS, the participant used the adjective Arabic after the English noun class, violating the constraint since English attributive adjectives come before nouns. Another example that violates the constraint is (38) in which the participant used the Arabic possessive second person pronoun tab3oonak (your) after the English noun ideas which clearly violates the English structure.

37. Saba7 el class el3arabi on a Frimorning morning the the-Arabic 
'What a lovely morning for the Arabic class on a Friday morning.'

38. Wallah el ideas tab3oonak smart....lol

God the yours laugh out loud

'By god, your ideas are smart.'

The data of this study proves my hypothesis wrong and proves the invalidity and non-universality of the Equivalence Constraint since it cannot prevent the occurrence of code-switching between Arabic and English at points where there is a difference between the structures of the two languages. My findings support previous research findings on oral conversations CS that Poplack's constraint is not universal even on CMC code-switching. Bentahila and Davies (1983), Berk-Seligson (1986), Al-Mansour (1999), Alenezi (2001), Al-Qudhai'een (2003) reported that Poplack's constraint was violated in their studies and proved that it lacks universality.

\section{CONCLUSION}

The findings of my study indicate that Jordanian bilinguals are able to use different types of CS, and this can be ascribed to their high level of proficiency, which also supports Poplack's (1980) findings that there is a correlation between high competence of L2 and high frequency in all types of CS. The findings also show that nouns and noun phrases are the most frequently used type of switches among the other syntactic categories, i.e., verbs and verb phrases, adjectives, adverbs, prepositions and prepositional phrases, and pronouns. Regarding the syntactic constraints proposed by Poplack (1980), the results obviously show that there is a violation to the two constraints, namely The Free Morpheme Constraint and The Equivalence Constraint. Moreover, the suitability of the Free Morpheme Constraint to the written communications or CMC has been invalidated due to lack of information on the phonological integration of an English lexical item to an Arabic bound morpheme. Thus, this constraint was never designed for this sort of use.

\section{References}

Al-Deaibes, M. Gemination: Weight or Length? Evidence from Rural Jordanian Arabic. Word, 66 (2), 2021.

Al-Deaibes, M. and Rosen, N. Gemination in Rural Jordanian Arabic. In Amel Khalfaoui and Matthew A. Tucker (eds.), XXX Perspectives on Arabic 
Linguistics, pp. 53-76. Amsterdam/ Philadelphia: John Benjamins Publishing Company, 2019.

Al-Deaibes, M. The phonetics and phonology of assimilation and gemination in Rural Jordanian Arabic. PhD Dissertation, University of Manitoba, 2016.

Al-Deaibes, M. Code-switching on Facebook: Structural constraints. In Aubrey Healey, Ricardo Napoleão de Souza, Pavlína Pešková, and Moses Allen (eds.). Proceedings of the 11th High Desert Linguistics Society, 30-43. University of New Mexico, 2016a.

Abalhassan, K. and Alshalawi, Hamdan. Code-switching behavior of Arab speakers of English as a second language in the United States. Intercultural Communication Studies, 10, 179-188, 2000.

Aboelezz, M. Latinized Arabic and connections to bilingual ability. Papers from the Lancaster University Postgraduate Conference, Vol. 3: Edited by Steve Disney, Bernhard Forchtner, Wesam Ibrahim \& Neil Miller, 2009

Alenezi, F. H. Formal constraints on Arabic/English code-switching: a lexicallybased approach. Unpublished Ph.D. dissertation, University of Kansas, Kansas, 2001.

Al-Enazi, M. H. The Syntactic form and social functions of Saudi Arabic-English code-switching among bilingual Saudis in the United States. Unpublished Ph.D. dissertation, Indiana University of Pennsylvania, Indiana, 2002.

Al-Khatib, M. and Sabbah, E. Language choice in mobile text messages among Jordanian university students. SKY Journal of Linguistics, 21, 37-65, 2008.

Al-Mansour, N. Linguistic constraints on code-switching: A case study of SaudiSpoken Arabic-English code-switching. Doctoral Dissertation, University of Florida, 1998.

Al-Qudhai'een, M., A. I. The syntax of Saudi Arabic-English intrasentential codeswitching. Doctoral Dissertation, The University of Arizona), 2003.

Bader, Y., and Minnis, D. D. Morphological and syntactic code-switching in the speech of an Arabic-English bilingual child. Multilingua, 19(4), 383-403, 2000.

Bentahila, A., and Davies, D. The syntax of Arabic-French code-switching. Lingua 59: 301-30, 1983.

Berk-Seligson, S. (Linguistic constraints on intersentential code-switching: A case study of Spanish/Hebrew bilingualism. Language in Society 15 (3): 313-348, 1986.

Crystal, D. Language and the internet (2nd ed.). New York, NY: Cambridge University Press, 2006.

Durham, M. Language choice on a Swiss mailing list. Journal of ComputerMediated Communication 9: 1, 2003.

Ghanem, R. Arabizi is destroying the Arabic language. Arab News. 18:233, 2001.

Ho, W. J. Functional complementarity between two languages in ICQ. International Journal of Bilingualism 10 (4), 429-421, 2006.

Kanakri, $\mathrm{M}$ and lonescu, V. Prototypes of code-switching in the speech of Romanian/Arabic bilinguals in Jordan. Jordan Journal of Modern Languages and Literature, 2, 179-194, 2010. 
Mustafawi, E. Lone English-origin nouns in Arabic discourse: Codeswitches or borrowings? In S. Burelle \& S. Somesfalean (eds.), Proceedings of the Canadian Linguistic Association, pp. 219-231. University du Quebec a Montreal, 2002.

Muysken, P. Bilingual speech. A typology of code-switching. Oxford: Cambridge University Press, 2000.

Palfreyman, D. and Al Khalil, M. A funky language for teenzz to use: representing gulf Arabic in instant messaging. Journal of ComputerMediated Communication, 9, 1, 2003.

Poplack, S. Sometimes I'll start a sentence in Spanish y termino en español. Linguistics 18: 581-618, 1980.

Poplack, S. Contrasting patterns of code-switching in two communities. In M. Heller (Ed.), Codeswitching: anthropological and sociolinguistic perspective (pp. 215-244). New York: Mouton de Gruyter, 1988.

\section{التحول اللغوي على الفيسبوك من قبل ثناييي اللغة الأردنيين}

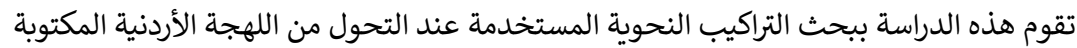

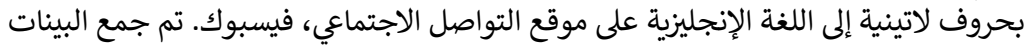

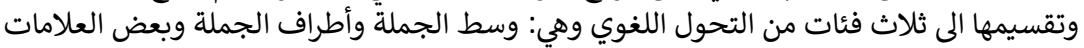

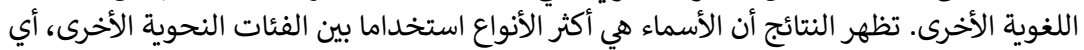

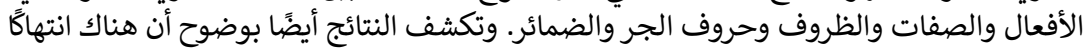

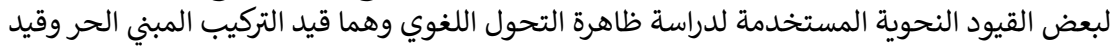

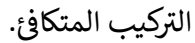

$$
\text { الكلمات الدالة: التحول اللغوي، العربية اللاتينية، التراكيب النحوية، اللهجة الارنية }
$$

